\title{
Effect of Learning and Strategy Formal Reasoning of Learning Outcomes Science Junior High School in Medan City
}

\author{
Marolop Hutagaol \\ Departement of Junior High School $41^{\text {th }}$ Medan \\ Medan - Indonesia \\ e-mail: medan.smp41@gmail.com \\ Abdul Muin Sibuea \\ Departement Education Technology \\ State University of Medan \\ Medan - Indonesia \\ Julaga Situmorang \\ Departement of Education Technology \\ State University of Medan \\ Medan - Indonesia
}

\begin{abstract}
Abstrasct - The experiment was conducted at junior high school Medan City, field in 2011-2012. The sampling method is random sampling: 22, 21, 20 persons for discovery, inquiry and conventional, uses formal reasoning tests and results of junior high school students. Experimental studies using treatment with level $3 \times 2$ design. The findings of the study indicate there is a difference in learning achievement student science junior high school if learning with: (1) discovery, inquiry and conventional, (2) discovery than inquiry, (3) discovery than conventional, (4) inquiry than conventional, (5) there is interaction between formal reasoning and learning strategies, (6) who have a high formal reasoning when learning with discovery learning strategies compared than inquiry and conventional, (7) who have a high formal reasoning if learning with discovery compared than inquiry, (8) who have a high formal formal reasoning when learning with discovery than conventional, (9) who have a high formal reasoning with inquiry than conventional, (10) who have low formal reasoning when learning with discovery compared than inquiry, (11) who have low formal reasoning when learning with discovery compared than inquiry, (12) who have reasoning low formal learning discovery compared with learning conventional, (13) who have low formal reasoning when learning with inquiry than conventional.
\end{abstract}

Keywords-effect of learning strategy, discovery, inquiry, conventional, formal reasoning, science.

\section{INTRODUCTION}

Education is an effort for human beings to develop their potential through learning process known and recognized by the community. The 1945 constitution article 31 paragraph (1) states that every citizen is entitled to education, and paragraph (3) affirms that the government seeks and organizes a national education system that enhances faith and piety and noble character in order to educate the nation. (Ministry of National Education. Jakarta. 2006). $\{1\}$

Creating a fully Indonesian man requires a goverment that upholds the principles of democracy, decentralization, justice and human rights. These principles also have a fundamental impact on the need for changes to, process, management and implementation of education so that the emergence of new demands in all aspects of life including the demands of the need for renewal of the education system. Component of the education system that needs to experience diversification and change in improvement is that education unit level curriculum is expected to (1) better meet the demands of student needs (student oriented) and diverse regional needs, (2) more oriented to diversify the type of education professionally and (3) has a national graduation competency standard, but with due regard to the uniqueness of each region. (Charles $\mathrm{M}$. Reigeluth, Journal Educational Technology Researc and Development. 2006). $\{2\}$ 
The basic framework of the development and improvement of the learning process is the improvement of the curriculum and the process of learning implementation. The process and implementation of learning can be done in various ways such as improving services to students through learning strategies. It is necessary to apply a format that can be a guide for example establishing the syllabus is done in school, then activities that ensure the experience of students directly obtain process, product, competence based on authentic, accurate and sustainable assessment. To achieve all of that the managers of education must be able to design, mix and combine various activities for the achievement of high quality educational goals. (Brown W. 2010). $\{3\}$

The introduction research findings are intended to fill the need for development of lesson learning strategies that can reduce or minimize the gap between what exists (reality) and what is expected. Similarly, the results of student learning in junior high school of Medan city and the utilization of learning resources and learning strategies is not in accordance with the expected meaning there is still a gap between expectations and reality. The above ideas still require proof of academic proof, for that research is done with the title: "The influence of learning strategies and formal reasoning on the results of science learning in junior high school Medan city" with the aim to know: (1) differences in the results of science learning junior high school students learning with discovery, inquiry and conventional learning strategies, (2) with discovery compared to inquiry learning strategy, (3) with discovery compared to conventional learning strategy, (4) with inquiry compared to conventional learning strategy, (5) The interaction between learning strategies and formal reasoning on the learning outcomes of science students of junior high school, (6) differences in learning outcomes of secondary school students who have high formal reasoning when learning with discovery compared with those studied with inquiry, and conventional learning strategy, (7) with discovery compared with those studied with inquiry learning strategy, (8) with discovery compared with conventional learning strategy, (9) with inquiry compared with conventional learning strategy, (10) differences in learning outcomes of secondary school students who have low formal reasoning when learning with discovery compared with inquiry, and conventional learning strategy, (11) with discovery compared with inquiry learning strategy, (12) with discovery compared with conventional learning strategy, (13) with inquiry compared with conventional learning strategy.

\section{Research Purpose}

The purpose of this research is theoretically, it is expected to: Enrich or provide support in the development of science in the field of learning strategies, particularly in the areas of discovery, inquiry and conventional learning strategies especially those related to the students formal reasoning of the student's learning outcomes; Providing thought contribution to the study of science learning outcomes for the science education department of state Medan university; contribute to researchers, especially in researching discovery, inquiry and conventional learning strategies and students formal reasoning.

Learning is the relatively permanent change in persons knowledge or behavior due to experience. (Rita C. Richey, 1986). $\{4\}$

Usefulness of the results of research is practical, is expected to provide: contribution or input means for junior high school in improving science learning outcomes, especially through the implementation of discovery, inquiry and conventional learning strategies and through formal student reasoning, contribution or meaningful input in the thinking and determination of alternative learning strategies in science subjects at junior high school level, input or add knowledge and insight into learning strategies for researchers, as well as to gain experience in analyzing the learning outcomes of science, the context of discovery, inquiry and conventional learning strategies in relation to students' formal reasoning, input or as written information as a valuable reference for readers about discovery, inquiry and conventional learning strategies and students formal reasoning as well as their impact on improving student learning outcomes.

\section{METHODS}

The method used is the experimental teatment method by level $3 \times 2$. The research method used is quasi experiment which is experimental research done to the class/group that has been formed before, with: one class is given treatment discovery, one class/ group is treated inquiry, and one classes/ other groups are treated with conventional learning strategy. The design of the research used is the design of ANAVA $3 \mathrm{X} 2$ with the paradigm as the following Figure 1:

\begin{tabular}{|l|c|c|c|}
\hline \multirow{2}{*}{$\begin{array}{c}\text { Formal } \\
\text { Reasoning }\end{array}$} & \multicolumn{3}{|c|}{ Learning Strategies } \\
\cline { 2 - 4 } & Discovery (A1) & Inquiry (A2) & Conventional (A3) \\
\hline High (B1) & A1B1 & A2B1 & A3B1 \\
\hline Low (B2) & A1B2 & A2B2 & A3B2 \\
\hline
\end{tabular}

Figure 1: Paradigm design of ANAVA $3 \times 2$

Information:

(A1) Discovery learning strategy

(A2) Inquiry learning strategy

(A3) Conventional learning strategy

(B1) High reasoning formal

(B2) Low reasoning formal

A1B1 Discovery learning strategy with high formal reasoning

A1B2 Discovery learning strategy with low formal reasoning

A2B1 Inquiry learning strategy with high formal reasoning

A2B2 Inquiry learning strategy with low formal reasoning

A3B1 Conventional learning strategy with high formal reasoning

A3B2 Conventional learning strategy with low formal reasoning 


\section{RESULTS AND DISCUSSION}

The results showed: There was a difference learning outcomes student science of junior high school who studied with discovery, inquiry and conventional learning strategies. There is a difference of learning outcomes science of junior high school students who learn with discovery compared with inquiry learning strategy. There is a difference of science learning outcomes of junior high school students who learn with discovery compared to conventional learning strategy. There is a difference in the learning outcomes of secondary school students who are learning with inquiry compared with conventional learning strategy. There is an interaction between learning strategy and formal reasoning on the learning outcomes of junior high school students;

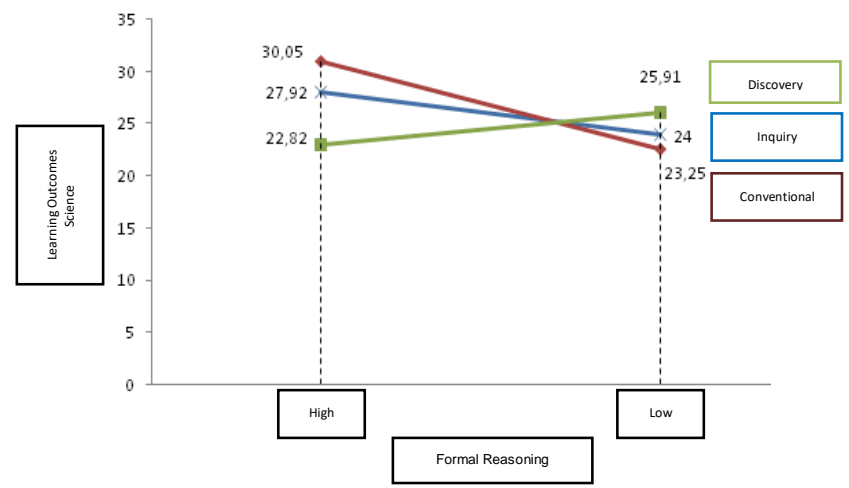

Figure 2.

Visualisai Interaction between learning strategy and formal reasoning on the learning outcomes sciense of junior high school student

There is a difference in the results science of junior high school students who have high formal reasoning when learning with discovery compared with inquiry, and conventional learning strategy; There is a difference in the results of science study of junior high school students who have high formal reasoning when learning with discovery compared with inquiry learning strategy; There is a difference in learning outcomes of secondary school students who have high formal reasoning when learning with discovery compared with conventional learning strategy; There is a difference in the learning outcomes of the junior high school students who have high formal reasoning when learning with inquiry compared with conventional learning strategy; There is a difference in learning outcomes of secondary school students who have low formal reasoning when learning with discovery compared with those studied with inquiry and conventional learning strategy; There is a difference in the learning outcomes of secondary school students who have low formal reasoning when learning with discovery compared with inquiry learning strategy; There is a difference in the learning outcomes of secondary school students who have low formal reasoning when learning with discovery compared with conventional learning strategy; There is a difference in the learning outcomes of secondary school students who have low formal reasoning when learning with inquiry compared with conventional learning strategy.

The result of research using 2 factorial variance $3 \times 2$ showed that there are differences of science learning outcomes between students learning with discovery compared with inquiry and conventional learning strategy. The results of the advanced test analysis using Scheffe test from the average group, where the average score of science learning outcomes of junior high school students learning with discovery is higher than that of students learning with inquiry learning strategy. The learning outcomes of sciense of junior high school students who studied with discovery were higher than those of students learning with conventional learning strategy. Similarly, the learning outcomes of sciense of junior high school students who studied with inquiry were higher than those of students learning with conventional learning strategy. This research peveals that formal reasoning has a significant influence on the achievement of science learning outcomes of junior high students in other words that the learning outcomes of science fron students who have high reasoning differences significantly cọmpared with students who have low formal reasoning. The result of science study of junior high school students who have high formal reasoning is higher than the student learning outcomes that have low formal reasoning. In relation to the findings of the above results to improve the students' learning outcomes, the following efforts should be undertaken: to give students the freedom to develop ideas, insights and imaginations on how to intensify learning. The development of ideas and insights will broaden the horizon of students viewpoints and ultimately create opportunities for the growth of improved science learning outcomes, develop imagination with long-term orientation skills, so that students are not fixated on temporary successes but still strive for sustainability, develop the initiative and interest of students to do something new in new ways, to gain new experience without fear of failure. Success or failure is part of learning creativity, developing the nature of the curiosity as an effort to develop productive mindset and developing creative products, encourage the growth of spirit and confidence to be more courageous in expressing opinions, firm in principle, no doubt on self-esteem, and the growth of confidence will develop a person's creativity, create a climate or atmosphere of practice conducive to the growth of creativity, create learning appeal so that what they follow and do in practice becomes fun, active training needs to be developed by providing opportunities for cognitive development, dynamic behavior and encouraging the creativity of the practice 
The results showed that there was a difference of learning outcomes of sciense of junior high school students who studied with discovery compared with conventional learning strategy. The results of advanced test analysis using Scheffe test from the average group, where the average score of science learning outcomes of students learning with discovery is higher than students who learn with conventional learning strategy. This indicates that discovery is more appropriate in improving students understanding of science learning outcomes compared with conventional learning strategy for students of junior high school state $3^{\text {th }}$ and $7^{\text {th }}$ Medan at a significant $(\alpha) 0.05$ level. These results indicate that to study the subject matter of science is more appropriate using discovery than by using conventional learning strategy.

The results showed that there were differences in the learning outcomes of the junior high school students who studied with inquiry compared with conventional learning strategy. The results of advanced test analysis using Scheffe test from the average group, where the average score of science learning outcomes of students learning with inquiry is higher than students who learn with conventional learning strategy. This indicates that inquiry learning strategy is more appropriate in improving students understanding of science learning outcomes compared with conventional learning strategy. for students of junior high school state $3^{\text {th }}$ and $7^{\text {th }}$ Medan at a significant level $(\alpha) 0.05$. These results indicate that to study the subject matter about science is more appropriate using inquiry compared to using conventional learning strategy.

Interaction between learning strategy and formal reasoning on science learning outcomes of junior high school students. The research findings show that there is an interaction between the learning strategy and the students' formal reasoning on the science learning outcomes of students of junior high school state $3^{\text {th }}$ and $7^{\text {th }}$ Medan. Thus, that the learning strategy and formal reasoning of students have a significant influence on the learning outcomes of science students. Students who have high and low formal reasoning by following discovery, inquiry and conventional learning strategy can have an effect on the learning outcomes of junior high school students. This indicates an interaction between the learning strategy and the students' formal reasoning on the competence of science learning outcomes. Formal reasoning is the capacity of an individual to perform various tasks in a job.

Students with low formal reasoning will have difficulty constructing or constructing knowledge and skills from the science learning outcomes they need, because students with low formal reasoning have low rates of speed in solving problems caused by their low retention and memory. Students with low formal reasoning will experience difficulties in solving the problem of mastery of the material or problems it faces, because the knowledge and skills possessed based on the information notified by the teacher is not because found by him, in other words the process of learning is the transfer of knowledge from teacher to student. Such a learning strategy is a form of learning in which the class still focuses on the teacher as the main source of knowledge, then lectures and experiments in the form of a practicum become the main alternative. In addition, knowledge is only considered as a set of facts that must be memorized and analyzed and less developed the results of science learning. Students who have high formal reasoning, students will be able to create and identify problem-solving alternatives, be able to select and determine the essential materials for their learning needs. Students with high formal reasoning can quickly adapt, adjust what is known or stored in their long-term memory to be learned or faced.

The result of research using 2 factorial variance $3 \times 2$ showed that there are differences of science learning outcomes of junior high school students who have high formal reasoning that learn with discovery compared with inquiry and conventional learning strategy. The results of the advanced test analysis using Scheffe test from the average group, where the average score of science learning outcomes of junior high school students who have high formal reasoning who learn with discovery is higher compared with students learning with inquiry learning strategy. The learning outcomes of sciense of junior high school students who studied with discovery were higher than those of students learning with conventional learning strategy. Similarly, the result of science learning of junior high school students who studied with inquiry is higher than students who learn with conventional learning strategy.

The results showed that there was a difference of learning outcomes of sciense of junior high school students who had high formal reasoning that studied with discovery compared with inquiry learning strategy. The results of the advanced test analysis using Scheffe test from the average group, where the average score of science learning outcomes of students learning with discovery is higher compared with students learning with inquiry learning strategy. This indicates that discovery is more appropriate in improving students understanding of students science learning outcomes with high formal reasoning compared with inquiry for students of junior high school state $3^{\text {th }}$ and $7^{\text {th }}$ Medan city at a significant $(\alpha)$ 0.05 level.

This result shows that to study the subject matter about science is more appropriate to use discovery compared with using inquiry in students who have high formal reasoning. The results showed that there was a difference of learning outcomes of sciense of junior high school students who had high formal reasoning that studied with discovery compared with inquiry learning strategy. The results of the advanced test analysis using Scheffe test from the average group, where the average score of science learning outcomes of students learning with discovery is higher compared with students 
learning with inquiry learning strategy. This indicates that discovery is more appropriate in improving students understanding of science learning outcomes compared to inquiry learning strategy for students of junior high school state $3^{\text {th }}$ and $7^{\text {th }}$ Medan city at a significant $(\alpha) 0.05$ level. These results indicate that to study the subject matter of science is more appropriate to use discovery than by using inquiry learning strategy for students with high formal reasoning.

The results showed that there was a difference of learning outcomes of sciense of junior high school students who had high formal reasoning that studied with discovery compared with inquiry learning strategy. The results of the advanced test analysis using Scheffe test from the average group, where the average score of science learning outcomes of students learning with discovery is higher compared with students learning with inquiry learning strategy. This indicates that discovery is more appropriate in improving students understanding of science learning outcomes compared to inquiry learning strategy for students of junior high school state $3^{\text {th }}$ and $7^{\text {th }}$ Medan city at a significant $(\alpha) 0.05$ level.

This result shows that to study the subject matter about science is more appropriate to use discovery than using inquiry learning strategy for students who have high formal reasoning. The result of research using 2 factorial variance $3 \times 2$ shows that there are differences of science learning result of junior high school students who have low formal reasoning between students who learn with discovery compared with inquiry, and conventional learning strategy. The results of the advanced test analysis using Scheffe test from the average group, where the average score of science learning outcomes of junior high school students learning with discovery is higher than that of students learning with inquiry learning strategy. The learning outcomes of sciense of junior high school students who studied with discovery were higher than those of students learning with conventional learning strategy. Similarly, the results of sciense study of junior high school students who studied with inquiry were higher than those students who studied with conventional learning strategy for students had low formal reasoning.

The results showed that there were differences in the learning outcomes of secondary school students who had low formal reasoning who studied with discovery compared to inquiry learning strategy. The results of the advanced test analysis using Scheffe test from the average group, where the average score of science learning outcomes of students learning with discovery is lower compared with students who learn with inquiry learning strategy. This indicates that inquiry is more appropriate in improving students understanding of science learning outcomes compared with discovery for students of junior high school state $3^{\text {th }}$ and $7^{\text {th }}$ Medan city at a significant ( $\alpha$ ) 0.05 level. These results indicate that to study the subject matter about science is more appropriate using inquiry than using discovery learning strategy for students with low formal reasoning.

The results showed that there were differences in the learning outcomes of secondary school students who had low formal reasoning who studied with discovery compared with conventional learning strategy. The results of the advanced test analysis using Scheffe test from the average group, where the average score of science learning outcomes of students learning with discovery is lower than students learning with conventional learning strategy. This indicates that the conventional is more appropriate in improving students understanding of science learning outcomes compared with discovery for students of junior high school state $3^{\text {th }}$ and $7^{\text {th }}$ Medan city at a significant level $(\alpha) 0.05$. These results indicate that to study the subject matter about science is more appropriate using conventional than using discovery learning strategy for students with low formal reasoning.

The results showed that there were differences in the results of science learning of junior high school students who had low formal reasoning who studied with inquiry compared with conventional learning strategy. The results of the advanced test analysis using Scheffe test from the average group, where the average score of science learning outcomes of students learning with inquiry is lower than students learning with conventional learning strategy. This indicates that the conventional is more appropriate in improving students understanding of science learning outcomes compared with inquiry for students of junior high school state $3^{\text {th }}$ and $7^{\text {th }}$ Medan city at a significant level $(\alpha) 0.05$. These results show that to study the subject matter about science is more appropriate using conventional than using inquiry for students with low formal reasoning. Discovery is a learning process that aims to help students see meaning in academic subjects with the context of their daily lives, that is with the context of personal, social, and cultural circumstances. To achieve this goal the system includes the following eight components: making meaningful connections, doing significant work, independent learning, collaborating, critical and creative thinking, nurturing individuals, achieving high standards, and using authentic judgments.

The objective of the discovery is to equip students with knowledge and skills that can flexibly be applied to solve real problems encountered in everyday life. discovery with its principles when carefully understood and scrutinized is possible to be applied in science learning especially in terms of practicum in the laboratory and the field. In the learning process students are trained to build their own knowledge in active involvement in the learning process. In the implementation of science learning there are seven components of discovery applied in the learning process, namely: constructivism, finding, asking, learning community, 
modeling, reflection, the real assessment. (Anna Sotter. 2008). $\{5\}$

Furthermore, to facilitate the activities of pratikum skills in the sciense there are five approaches that can be given to students: the teacher controls the student's activities as often as possible so that all students are active in practical skills activities, provide an opportunity for students to recognize their own findings so that each participant in the learning process, the skills of doing or doing themselves remain attractive, students are given the opportunity to perform roleplay according to ability, assist students in performing the skills of students skills felt cared for by the teacher in the move, practice skills in the laboratory, students are given a free opportunity in the corridor that has been determined.

The learning activities are an attempt to arrange a set of external events to facilitate the interpretation, construction, and manifestation of knowledge and skills for a student. (Robert Maribe Branch. 2009). $\{6\}$

There are four basic concepts in implementing skills development practices using the discovery approach: (a) provide various images relating to student situations, learning processes, learning experiences, education, schools, teachers, progress and culture, weaknesses and attitudes students to the learning process, (b) determining informants who know the problems and experience in providing answers, especially those related to schools, teachers, and learning processes that take place in the school. (c) encourage any group/ individual in the classroom to participate in or respond to any questions raised by the informant so as to be impressed that the situation is genuinely all interested students to practice, (d) determine the topic of discussion in accordance with the subject matter so that it is able and easy to solve the issue that arises. In addition to the topic that is determined related to the subject matter, the topic of conversation can also be displayed or adjusted to the circumstances surrounding the school. (Brown,G., Andeson, A., Shilcock, R., \& Yule, G. 1984). \{7\}

More specifically, in the context of discovery, teaching practice skills, is so that students can make observations and analysis.

When in the classroom the success of the practice involves: the prevalence of student participation in the sense that all students have the opportunity to do and contribute to the achievement of the objectives of the activity; the high motivation of students who are marked by their interest in the topic of activity and have something new to do; and; the acceptability of the tools used, in the sense that between one student and the other using a relevant and mutually understandable learning strategy.

\section{CONCLUSION}

The conclusions in this research as follows: Firstly, overall discovery, inquiry and conventional learning strategies influence the learning outcomes of secondary school students. Thus, to improve the learning outcomes of science students of junior high school can be done by using discovery, inquiry and conventional learning strategies. Secondly, there is an interaction between learning strategies and formal reasoning on the learning outcomes of science. From these findings it can be concluded that to improve the science learning outcomes students who have high formal reasoning can be done with discovery learning strategy, while for students who have low formal reasoning can be done with conventional learning strategy. Third, for junior high school having high formal reasoning, the learning outcomes of science students who studied with discovery learning strategy were higher than the students learning outcomes that studied with inquiry learning strategy. Fourth, for junior high school students who have low formal reasoning, the learning outcomes of students sciences learning with discovery learning strategy are lower than those of students learning with inquiry learning strategy. Fifth, the result of science learning of junior high school students who learn with discovery learning strategy is higher than the result of science learning of students who learn with conventional learning strategy. Sixth, the result of science learning of junior high school students learning with inquiry learning strategy is higher than the result of science learning of students who learn with conventional learning strategy. Seventh, the result of science learning of junior high school students learning with discovery learning strategy and inquiry learning strategy is higher than the result of science learning of students learning with conventional learning strategy. Eighth, the result of science learning of junior high school students who learn with conventional learning strategy is lower than the result of science learning of students who study with inquiry learning strategy.

\section{REFERENCES}

[1] Ministry of National Education. "National Education Ministerial Regulation on Content Standards for Units Primary and Secondary Education". Jakarta. 2006

[2] Reigeluth, C.M., "Functional Contextualism : An Ideal Frame Work for Theory in Instruction Design Technology" : Journal Educational Technology Research and Development, Vol.54. 2006

[3] Brown, W., "For your consideration on suggestions and reflections on teaching and learning", Paper student association forum on the cyber campus, University of North Carolina at Chapel Hill. 2010

[4] Rita C. Richey. "The Theoretical and Conceptual Bases of Instructional Design". Wayne State University, Kogan Page, New York. 1986

[5] Anna Sotter. "Practicing English Speaking Skill Through Small Group Discussion". Ohio State University Press. 2008

[6] Robert Maribe Branch. "Instructional Design: The Addie Approach". New York. Springer Science LLC. 2009

[7] Brown, G., Anderson A., Shilcock, R., \& Yule, G. "Teaching Talk: Strategies for Production and Assesment". Cambridge. Cambridge University Press. 1984 